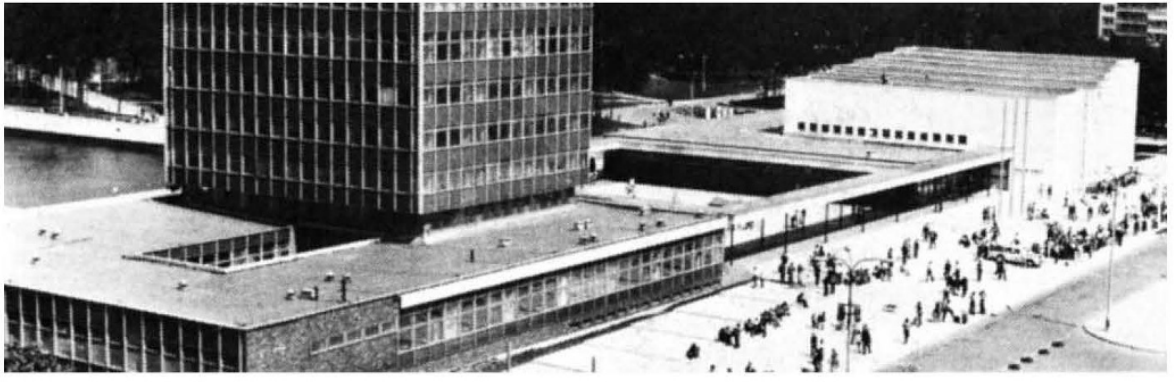

FIVE years ago, Torun University moved to a new campus in the suburb of Bielany, which thus became Poland's only "university village". In spite of this splendid new site, science at Torun, as elsewhere, is somewhat constrained by lack of finance. Never- theless, some interesting research is going forward on a relatively shoestring budget-a tradition going back to the difficult days of the university's foundation in the aftermath of World War II.

Report by Vera Rich

\title{
Torun: local conditions provide new possibilities for research
}

$\mathbf{A}^{\mathrm{c}}$ CCORDING to the official handbook of Torun University, the idea of a university for Pomerania (coastal Poland) has been advocated by its population since 1595. Not until the Nazi retreat of 1945, however, were any concreate plans put in motion.

Of the possible sites in the area, the other main contender, the former 'free city' of Gdansk, had suffered major devastation, and its famous Polytechnic Institute was virtually destroyed. Torun, however, being a quiet country town of little military importance and with strong historical ties with Germany had escaped the worst fury of the Third Reich.

To any advocate of the Oxbridge or Ivy League tradition, Torun is, indeed, an ideal site of a university a quiet township on the lower Vistula, whose old red brick and willow trees recall Hampton Court or Richmond. Moreover, Torun possessed the supreme advantage of having been the home-town of perhaps the most 'revolutionary' figure that Poland, that land of revolutions, ever produced. Accordingly, when the new university was formally established on 24 August, 1945 , it was given the official title of the Nicolaus Copernicus University in Torun.

Staffing the new university caused few problems. The frontier changes which had restored most of Torun's catchment area from Germany to Poland had also metamorphosed the former Polish university cities of Wilno and Lwów into Lithuanian Vil'nyus and Ukrainian L'viv. Former staff of the Stefan Batory University in Wilno provided the nucleus for Torun, augmented by a group from Lwów and a sprinkling from other Polish universities. In the case of physics, almost the whole former department from Wilno had disappeared during the war: only one remained, Professor Aleksander Jablonski, who, at the end of the war, found himself in Birmingham. Returning from England, he set about building up the physics institute virtually from scratch, and, by the time he retired had managed, in spite of a chronic lack of funds, to make the Torun school of physics world-famous in its own speciality - photoluminescence.

This particular field of research was chosen entirely pragmatically-Jablonski was himself an expert in photoluminescence; moreover, he knew that it is the cheapest field in which physicists may hope to do meaningful experimental work.

Financial difficulties, were, of course, most apparent in the early days, when, too, for a time (1951-56) there was the additional difficulty that national educational policy was geared to producing the professional cadres needed to rebuild the economy rather than education in the broader sense. Even now, however, financial controls still exist, particularly as regards imports of equipment from hard-currency areas. Although funds from the Polish government augmented by donations from academic and expatriate organisations throughout the world presented the university with a fine new campus in honour of the Copernicus quincentenary in 1973, the radio-astronomy department, for example, still lacks its promised second telescope which fell a victim to the world recession of the

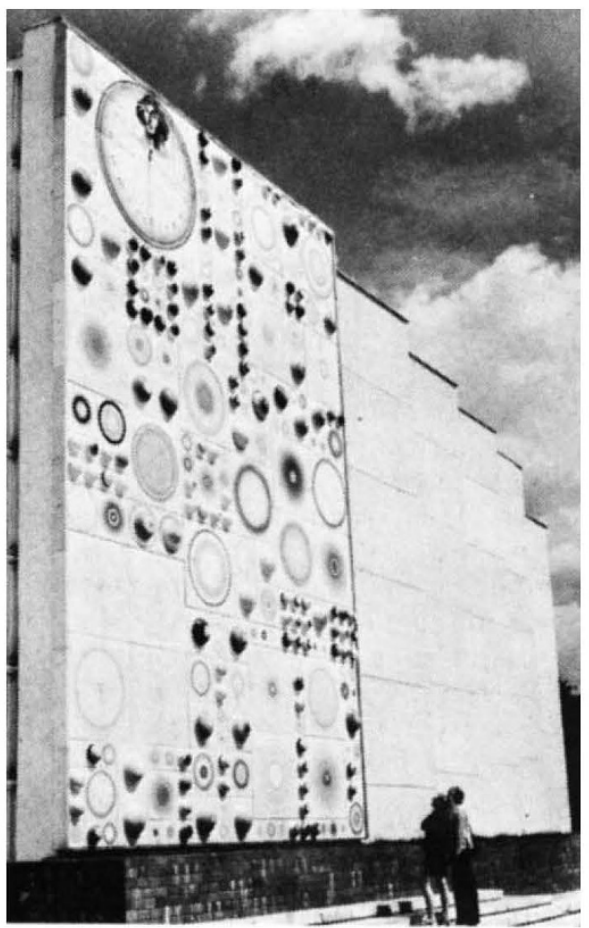

late 1960s.

Yet Torun still manages to do valuable work. Integration of research and industry is, of course, a major topic of all science policy discussions throughout the Comecon block, and Torun can show some useful examples of this ranging from desalination to artificial fibre production. What is more unusual is the extent to which it has proved possible to use local conditions to provide new possibilities for research.

This is perhaps most clearly seen in the work of the Biological Institute. This comprises 14 sections, ranging from anthropology to microbiology. Some of the most interesting work, however, is specifically related to the Polish, and, in particular, the Pomeranian environment.

Limnology, for example, is an obvious subject for a team so near the thousands of Masurian lakes. Although pollution, inevitably, must be taken into account, the Torun scientists are not primarily concerned with ecological hazards, but with charting the whole process of eutrophication-the increase of levels of various salts (notably of nitrogen and phosphorus), the degradation and deterioration of water-bodies in the course of the ageing of the ecosystem. However, the limnological team have not been content merely to observe existing lakes-abundant as these are in the vicinity. Since 1959, a now-classic study on the Koronowo Dam reservoir has been seeking to establish the rules of ecological succession. Before the construction of the dam was begun in 1959, the ecology of the river Brda was thoroughly investigated. Since then, three papers have been published and the fourth is at 
press, analysing the changing ecology of the lake over the years.

Another major field of biological research-plant hormones-is likewise related to local conditions. In Poland, as in all flat exposed regions, the lodging of wheat is a major cause of croploss. Since the use of fertilizers to improve yields also, normally, increases the stem length and, as a result, the likelihood of lodging, the use of growth-inhibiting hormones, notably CCC (chlorcholine chloride) was felt to be a valuable interim measure until reliable short-stemmed varieties of wheat are developed. Although, at present, there is some international concern about toxic side-effects of $\mathrm{CCC}$, this is by no means a set-back to the Torun team. Over the years, their work on plant hormones has far outstripped the immediate needs of agriculture. Theoretical studies are in progress on the role of hormones, notably the gibberellins, in flowering. Another major project, supported by the US Department of Agriculture, is investigating the role of the gibberellins in the growth of pine trees. Torun has ready access to an abundance of pineforests. Since working with trees is considerably more complicated than with small plants, not many biologists have been attracted into this particular sphere-hence the American interest in Torun. During the 15 years the project has been running, Dr Marian Michniewicz and his team have identified, extracted and purified a number of specific gibberellins in pine-trees.

Less happy, perhaps, is the position with research into sleep patterns and circadian rhythms. From the traditional subjects (rats, rabbits, hamsters), the project has progressed to birdschaffinches, starlings and rooks, captured by means of drugged grain, although some attempts have also been made to breed in captivity. The effect of impoverished and enriched environments, especially in rats, is also under investigation. According to $\mathrm{Dr}$ Juliusz Narebski, although it is fairly easy to provide an impoverished environment, enriched conditions are somewhat harder to ensure. Ideally, he said, they should be working with open-field conditions and miniaturised telemetry as is being done in the USA and in France. This, however, Poland cannot afford, so they must, perforce, continue with laboratory work only.

The physicists, however, have no choice but to obtain equipment by some means or other. Even in the relatively cheap field of photoluminescence, it is no cheap matter to fit out a research laboratory, to say nothing of the needs of students. The Physics Institute, indeed, seems to have benefited less than most from the quincentenary-it is still housed in a some-

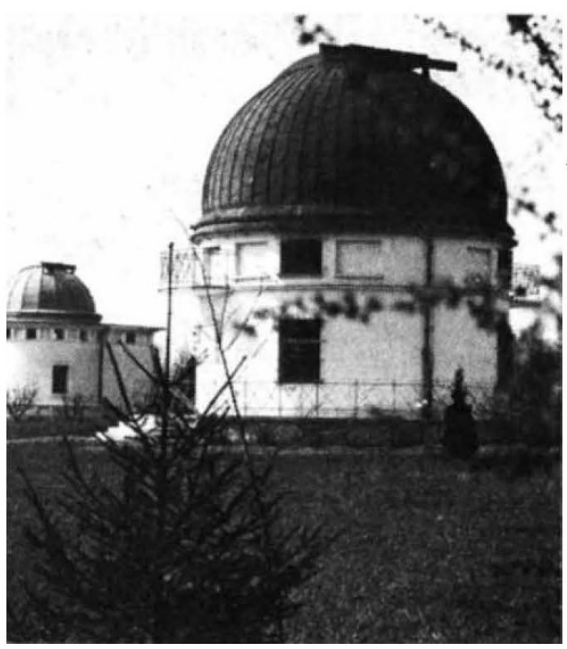

Radio astronomy at Torun: close cooperation with Cal Tech and Cambridge. Below: on campus at Poland's only university village.

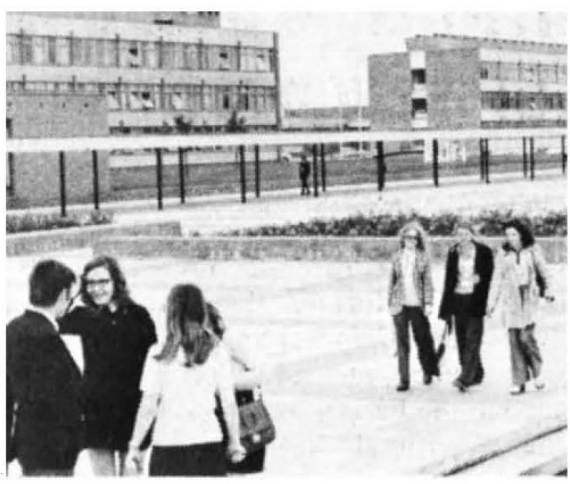

what old-fashioned building in the town, and the main advantage of 1973 was that the chemists moved to the new campus, leaving the physicists a few additional laboratories. However, equipment has been found from somewhere-the new apparatus for decay curves in the subnanosecond region is being assembled from a veritable united nations of components, with dials in German, Czech, English and Russian. In the students' laboratories, there are the usual standard experiments on the luminescence of dyes, optical and magnetic resonance, the Franck-Hertz experiment and so on; here, much of the apparatus seems to have come from Zeiss of Jena. But, in the fourth year of the five-year course, in the words of Dr Ryszard Bauer, the students "begin to do science" as well as studying it, carrying out programmes of tests not to confirm text-book results but as part of the on-going work of the institute. This part of their work is done downstairs, in a laboratory less well-appointed than the teaching laboratories upstairs, with the typical Torun research array of 'international' components, linked into a working set-up by ingenuity and a few home-manufactured essentials. 'Doing science', as opposed to 'studying' it, in Torun, must surely throw a whole new light on the idea of international cooperation.
This international trend is even more apparent in the radio-astronomy department. Torun University possesses the largest astronomical obervatory in Poland, and is doing valuable work both in the optical and radio fields. In optical astronomy, a spectral survey of 'peculiar' stars (novae, carbon stars, helium stars, variable stars) is in progress, a field of research especially associated with Dr Wilhelmina Iwanowska who retired recently.

The radio-astronomers are mostly concerned with the sun and the solar corona. Some interesting work has been done on the anomalies in the coronal scattering and refraction of stellar radio-emissions observed during the 1959 and 1970 solar maxima. Here, the Torun team work in close collaboration with $\mathrm{Cal}$ Tech and Cambridgeindeed, two of the team, Stanislaw Gorgolewski and Andrzej Kus actually trained in Cambridge under Sir Martin Ryle.

Cooperation stretches eastwards as well as west. When the Soviet Union offered to launch a Polish satellite as Copernicus-500, the Polish Academy of Sciences, who were officially responsible for the experiments, naturally approached Torun for suggestions. These were readily available; since the early 1960s Dr Gorgolewski had been advocating the use of a telemetry transmitter on a spacecraft-virtually a point source--to study the solar corona, and had suggested a similar experiment for the proposed Lunar International Laboratory that, in prerecession days, was expected to succeed the Apollo programme. In the end, virtually all the apparatus aboard Copernicus -500 was of Torun provenance.

Instrumentation is, indeed, one of $\mathrm{Dr}$ Gorgolewski's special interests. Currency restrictions and the very fact that radio-astronomy is a new science means that the institute has to design and construct the majority of the equipment it needs, although some vital components do come, often as gifts, from abroad. Not only does Dr Gorgolewski act as designer--he also closely supervises the whole construction process, down to the most ergonomic siting of a switch, and the measuring of the laminate housing. Thus a close involvement between scientist and instrument maker is established--and Dr Gorgolewski speaks no more proudly of his results in astrophysics than of the fact that his standard '19-inch' box for instruments has now become the Polish standard.

However practical and pragmatic the origin of this involvement, the result is an almost renaissance mutual interplay between the skills of scientist and craftsman, which rare as it is, seems particularly appropriate in a university named after Copernicus. 